\title{
Psychological Impact
}

National Cancer Institute

\section{Source}

National Cancer Institute. Psychological Impact. NCI Thesaurus. Code C16222.

The impact of sickness on the mental wellbeing of both the patient and the patient's family. 